\title{
QUANDO O APITO NÃO TOCOU: EXPERIÊNCIA OPERÁRIA E IDENTIDADE DE CLASSE EM UM BAIRRO OPERÁRIO EM DECLÍNIO (BARRETO - NiTERÓI) ${ }^{1}$
}

\author{
Luciana Wollmann ${ }^{2}$
}

\begin{abstract}
Resumo
0 presente trabalho tem como objetivo analisar como se deu o processo de resignificação de identidades sociais - sobretudo a "de classe" por parte dos antigos trabalhadores da Companhia Fluminense de Tecidos, centenária fábrica localizada no bairro do Barreto na cidade de Niterói/RJ, a partir do final da década de 1970, quando a Companhia começa a dar os seus primeiros sinais de crise e o bairro inicia um gradativo processo de esvaziamento industrial. É nosso interesse aqui perceber como a diminuição dos postos de trabalho, combinada à desestruturação do antigo bairro operário e à ausência de melhores oportunidades no presente, contribuíram para um reforço da identidade operária deste grupo de trabalhadores e corroboraram para um exercício de re-elaboração de sua própria trajetória de trabalho dedicado à Companhia.
\end{abstract}

Palavras-chave: Cia. Fluminense de tecidos. Identidades. Trabalhadores.

\footnotetext{
${ }^{1} 0$ presente trabalho é uma versão simplificada do primeiro capítulo da dissertação de mestrado intitulada Soou o apito: experiência operária e identidade de classe dos trabalhadores da Companhia Fluminense de Tecidos do Barreto - Niterói/ RJ, defendida pela autora no Programa de Pós Graduação em História Social do Território da Faculdade de Formação de Professores (FFP), da Universidade do Estado do Rio de Janeiro (UERJ), em janeiro de 2010.

${ }^{2}$ Mestre pelo Programa de Pós Graduação em História Social do Território da Faculdade de Formação de Professores (FFP) da Universidade do Estado do Rio de Janeiro (UERJ). luwollmann@ yahoo.com.br
} 


\title{
WHEN THE WHISTLE DIDN'T BLOW: WORKING EXPERIENCE AND CLASS IDENTITY IN A DECLINING WORKING NEIGHBORHOOD (BARRETO - NITERÓI)
}

\begin{abstract}
The objective of the present work is to analyze how the process of redefining social identities took place - especially "the class" from the old employees of theFluminenseFabric Company, a secular factory located in the neighborhood of Barretoin the city of Niterói - RJ, since the end of the seventies, when the Company started to show the initial signs of a crisis and the neighborhood began a gradual process of industrial exodus. It is our interest to understand how jobreduction, combined with the destructuringof the old working neighborhood and the lack of better opportunities in the current neighborhood, contributed to a strengthening of the workers identity of this group of workers and corroborated to an exercise of re-elaboration of its own labor trajectory dedicated to the Company.
\end{abstract}

Keywords: Cia. Fluminense de tecidos. Identities. Workers.

Para 0 trabalhador, o prazer de ficar quieto é esgotante. Mesmo que a casa em que habite sob um céu sem nuvens seja guarnecida de verdes, perfumada de flores e animada pelo gorjeio de pássaros, se ele está ocioso, permanece inacessível aos encantos da solidão. Mas, se, por acaso, o som ou o apito agudo de uma fábrica distante atinge o seu ouvido; se simplesmente ouve 0 estalido monótono dos trituradores de uma manufatura, logo sua fronte se ilumina... Já não sente o perfume requintado das flores. A fumaça das altas chaminés das fábricas, os golpes retumbantes da bigorna o fazem vibrar de alegria. Lembra os dias felizes de trabalho guiado pelo gênio do inventor. (Edouard Foucauld).

E era um apito e ia longe quando ela chamava. Um apito dolorido. Aquele apito, minha filha, que é a saudade da gente aqui. Ela inda levou apitando muito tempo. A gente marcava a hora pra sair, quando a fábrica apitar três vezes, você sai de casa, a gente combinava assim, entendeu? As amigas, mulheres dos funcionários, quando a gente queria ir a cinema, queria ir em algum lugar. Ó quando a fábrica der o terceiro apito a gente vai saindo, tá. (Maria José Barreto, a "Dona Zezé"). 
0 apito de uma fábrica quando toca, desde os primeiros tempos do surgimento da indústria capitalista, representa o início ou término de uma longa e exaustiva jornada de trabalho do operário. Exímio regulador do tempo, preciso em suas atribuições de transformar as horas em mercadoria, o apito de uma fábrica constitui uma das formas bem empregadas do capitalismo de adequar o tempo de trabalhador ao tempo do empregador.

No trecho apresentado, Foucauld parece transformar estes mecanismos "hábeis com a usura do tempo" (THOMPSON, 2005, p. 291) em poesia, ao passo que Maria José Barreto lembra com saudade do apito que marcava não o tempo do trabalho e sim o horário do cinema com as amigas.

Dona Maria José ingressou como funcionária administrativa da Cia. Fluminense de Tecidos (CFT) em 1945, ainda na menoridade. Lá conheceu Davi Barreto, também um funcionário da administração da fábrica e que após sucessivas promoções na empresa, chegou ao cargo de diretor o qual ocupou por quase 10 anos. Já Foucauld, é referenciado por Walter Benjamin como um "fisiólogo" da vida parisiense, um flaneur que observava atentamente a metamorfose dos personagens inseridos na cena urbana francesa em meados do século XIX (BENJAMIN, 1989, p. 36).

Não pretendemos fazer aqui nenhuma análise aprofundada das considerações de Benjamin sobre determinado tipo de produção literária da França oitocentista (BENJAMIN, 1989, p. 34). 0 que é interessante para nós, é perceber que mesmo separados pelo "tempo e espaço" os discursos de Foucauld e de Dona Maria José se aproximam. Ao lembrar do som do apito agudo, ambos falam dos "dias felizes de trabalho", da "saudade" dos dias em que a fábrica funcionava e tudo parecia melhor. Sem dúvida, a falência do presente contribui para a valorização do passado que "opera como referencial para o imaginário elaborar a diferença temporal, fazendo do passado um outro tempo possível" (CHAUÍ, 1989, p. 157). Mas não apenas isso. Ambos trechos destacados se referem ao papel de centralidade que o trabalho exerce na vida da classe-que-vive-do-trabalho, não só por razões óbvias de sobrevivência, mas também em seu aspecto simbólico, cultural, identitário.

Neste artigo analisaremos o impacto da crise e posterior fechamento da Companhia Fluminense de Tecidos em seus trabalhadores. Nosso objetivo é analisar como a diminuição dos postos de trabalho, combinada à desestruturação do antigo bairro operário e à ausência de melhores oportunidades no presente, contribuíram para um reforço da identidade operária deste grupo. Não raro encontramos relatos de amizades, casamentos, vizinhança. Histórias de vida e de 
trabalho e outras tantas curiosas "que contaram" ou que "se ouviu dizer" sobre os companheiros de seção, chefes e patrões. Repetidamente, a palavra "saudade" é proferida nos depoimentos. Este forte saudosismo que inevitavelmente emociona e que ao mesmo tempo gera estranheza ${ }^{3}$, assim como a ênfase dos entrevistados em temas como solidariedade, amizade, valores e finalmente, o "gosto pelo trabalho", é que irá direcionar a nossa análise.

É importante considerar, no entanto, que este exercício de "idealização do passado" por parte dos entrevistados em contraponto com o presente, considerado um tempo de "falência", "abandono", "vazio" sugerem considerações relevantes a serem observadas, mas não revelam um fim em si mesmas. Não se trata aqui de uma equação, na qual dois fatores: passado + trabalho = tempo próspero; presente + falência = escassez, levam a um produto específico e sim como a combinação de determinados elementos concernentes à memória de trabalho dos entrevistados ganham nuances valorativas no que diz respeito à sua "boa" conduta no trabalho, no relacionamento com colegas, patrões e supervisores, à sua felicidade em trabalhar naquela determinada função sem, ao mesmo tempo, deixar de levar em conta as dificuldades na produção, a resistência física e psíquica exigidas pelo trabalho desgastante, o clima tenso das seções que precisavam "tirar a produção", o calor, a poeira, o mau cheiro, a vigilância constante, as dificuldades para se alimentar, para ir ao banheiro, que também de forma recorrente e não por acaso, são lembrados pelos trabalhadores entrevistados.

É necessário, portanto, situar "o lugar da fala" ou seja, como as motivações do presente incentivam continuamente uma nova re-leitura do passado, e ainda, como estas vão sendo recompostas com outras, mais antigas, conformando matizes únicas. Trata-se, sem dúvida, de um movimento dialético que envolve 0 novo e o velho, o interno e externo, o individual e o coletivo, que não são de forma alguma metricamente mensuráveis ou dotados de "unidade" ou determinismos sociais, mas sim inteligíveis, passíveis de identificação e interpretação.

\footnotetext{
${ }^{3} 0$ estranhamento se dá quando nos deparamos com o regime e condições de trabalho existentes em indústrias têxteis tradicionais, tal qual a CFT. Além do trabalho descontínuo e profundamente hierarquizado, o trabalho na fabricação de tecidos submetia o trabalhador a condições de trabalho bastante insalubres, já que as altas temperaturas, o barulho intenso, a poeira da fiação e tecelagem e o cheiro forte de tinta da estamparia se apresentavam como condicionantes necessários à produção. Ainda que se tomassem medidas preventivas a fim de minimizar estes riscos ocupacionais, o ambiente de trabalho oferecia graves riscos à saúde do trabalhador. A iminência de acidentes, o salário por produção, a rigidez nas medidas disciplinares, o trabalho pesado e exaustivo também constituem características deste tipo de produção industrial e são amplamente citados pelos trabalhadores entrevistados.
} 
Tentar situar-se em pensamento no lugar que o pesquisado ocupa no espaço social para o necessitar a partir desse ponto e para decidir-se de alguma maneira por ele [...], não é executar a 'projeção de si para outrem' do qual falam os fenomenólogos. É dar-se uma compreensão genérica e genética do que ele é, fundada no domínio (teórico ou prático) das condições sociais das quais ele é o produto: domínio das condições de existência e dos mecanismos sociais cujos efeitos são exercidos sobre o conjunto da categoria da qual eles fazem parte (a dos estudantes, dos operários, dos magistrados, etc.) e domínio dos condicionamentos inseparavelmente psíquicos e sociais associados à sua posição e à sua trajetória particulares no espaço social (BOURDIEU, 1997, p. 699).

Esta compreensão dos atores sociais em questão, de que nos fala Pierre Bourdieu, deve ir além da realização da entrevista pura e simples. É necessário perceber as "condições sociais das quais ele é produto", para se estabelecer verdadeiramente uma interação entre entrevistador e entrevistado. Para além de outras considerações empíricas acerca do trabalho de campo igualmente relevantes, mas que não nos cabe aqui detalhar, o sociólogo argüi sobre a necessidade de o pesquisador atentar, em qualquer produção discursiva, para a relação com os "condicionamentos inseparavelmente psíquicos e sociais", ou seja, o seu babitus que associado "à sua posição e à sua trajetória particulares no espaço social" (BOURDIEU, 1997, p. 700), ou seja, a sua auto-construção (THOMPSON, 1987, p. 12), permite que nos aproximemos um pouco mais de sua experiência.

Conscientes da impossibilidade de dar conta por completo deste processo, visto que estamos tratando de sujeitos sociais que se distinguem não só pela subjetividade, mas pela combinação de novas e velhas identidades - intrínsecas ou extrínsecas ao sujeito que podem surgir ou vir à tona a partir de sua própria experiência, concentrar-nos-emos aqui no caráter coletivo desta construção, que se caracteriza pelo reforço da identidade operária deste grupo social. Ao mesmo tempo, não perderemos de vista as possíveis divergências verificadas no interior deste grupo, gerando em muitos momentos ou situações uma variabilidade não tão tranqüila de se identificar, porém não menos instigante de se analisar.

Essas "divisões da memória” como nos recorda Alessandro Portelli (1996), não podem ser aqui pormenorizadas. No entanto, para além das cisões e sem que abandonemos a subjetividade, é nosso interesse aqui perceber como a identidade de classe, que é inerente à história deste grupo de trabalhadores, funcionou como um importante constructo em suas narrativas, sobretudo quando estes se viram imersos em um contexto de mudança e crise.

A classe acontece quando alguns homens, como resultado de experiências 
comuns (herdadas ou partilhadas), sentem e articulam a identidade de seus interesses entre si, e contra outros homens cujos interesses diferem (e geralmente se opõem) dos seus. A experiência de classe é determinada, em grande medida, pelas relações de produção em que os homens nasceram - ou entraram involuntariamente (THOMPSON, 1987, p. 10).

Para muitos, falar em identidade de classe pode parecer um esforço inócuo diante das tantas transformações do capitalismo, que cada vez mais se flexibiliza e em um mundo que intensamente se globaliza. Esta crítica pode se tornar ainda mais veemente quando conduzida ao nosso estudo, que enfatiza a importância da classe na construção das identidades sociais em um grupo de trabalhadores espacialmente localizado e inserido num contexto de crise do capitalismo mundial, quando velhos paradigmas que outrora estabeleciam as regras para o mundo do trabalho vão, aos poucos, sendo substituídos por outros, menos rígidos, palpáveis e o espaço, por sua vez, parece ganhar mais fluidez, menos comensurabilidade.

É claro que não pretendemos esmiuçar aqui este extenso debate com os teóricos mais afeitos às interpretações pós-modernas, ou que delas se aproximam. Ao invés disso, nos concentraremos em discutir como a identidade de classe ganhou especial protagonismo na fala dos entrevistados, assim como a categoria trabalho adquiriu dimensões idealizadas, a partir da desestruturação daquilo que eles acreditavam fazer parte.

Durante a elaboração da referida pesquisa, foram realizadas vinte e quatro entrevistas com ex-trabalhadores da Cia. Fluminense de Tecidos, que foram ou ainda são moradores do bairro Barreto ou áreas circunvizinhas ${ }^{4}$, dentre as quais, apenas cinco serão aqui apresentadas, a fim de melhor subsidiar a nossa argumentação. Ainda que a nossa pesquisa não obedeça a um recorte cronológico determinante, no que diz respeito à seleção e organização das entrevistas, acabamos utilizando como critério de identificação dos entrevistados justamente o período em que trabalharam na CFT, já que entre os depoentes encontramos trabalhadores que ingressaram na fábrica da década de 1940 à década de 1980. Em termos metodológicos, optamos por seguir as orientações de José Carlos Sebe Bom Mehy (1996) e estabelecemos como Colônia as pessoas que trabalharam na Cia. Fluminense de Tecidos e que vivem ou viveram no bairro do Barreto ou áreas circunvizinhas. Dentro da Colônia, constituímos duas redes: uma de

\footnotetext{
${ }^{4}$ Referimo-nos aqui aos bairros localizados em áreas limítrofes ao bairro do Barreto, tais como o bairro da Engenhoca e Venda da Cruz, localizados na cidade de Niterói e o bairro de Neves localizado em São Gonçalo.
} 
trabalhadores da CFT que trabalharam na fábrica antes de 1970 (Rede A) e a outra de trabalhadores que ingressaram neste estabelecimento fabril após esta data (Rede B) $)^{5}$.

Esclarecemos que tal critério não se deu apenas por uma questão puramente organizacional. Desde quando fizemos as primeiras entrevistas para esta pesquisa, identificamos que muitos dos ex-trabalhadores da CFT estabelecem um recorte temporal bem nítido no que diz respeito ao regime de trabalho da fábrica e à prosperidade do bairro. 0 primeiro momento, caracterizado pelo "tempo de Seu Eduardo Pai", é visto como um período de "pleno emprego", pouca rotatividade de mão-de-obra, diversidade do comércio e variedade nas opções de lazer e moradia da região. 0 segundo momento, considerado de falência e escassez, refere-se à administração dos herdeiros do Seu Eduardo, quando as antigas relações existentes vão, aos poucos, sendo rompidas dando lugar a novas relações mais individualizadas, mercantilizadas. Como foi a partir da década de 1970 que os filhos de Eduardo Haddad, Ricardo e Eduardo Haddad Filho começaram a tomar parte dos negócios da família - situação esta que vai se consolidando ao longo desta década e o início dos anos 80 - optamos por utilizar este marco cronológico como uma espécie de "critério diferenciador" entre os entrevistados, ainda que, reiteramos, muitos jovens trabalhadores corroborassem determinadas posições dos mais velhos.

Para melhor organização e compreensão das nossas idéias, dividimos este artigo em duas partes. Na primeira, apresentaremos uma breve síntese da trajetória da CFT, procurando situar os seus momentos de apogeu e crise; na segunda, discutiremos de que forma a categoria trabalho acabou sendo re-significada pelo grupo de trabalhadores que estamos estudando e como tal processo contribuiu para a re-elaboração de suas identidades sociais e de sua própria trajetória.

\section{QUANDO O APITO NÃO TOCOU}

Instalada em local outrora ocupado por chácaras, a Companhia Manufatora Fluminense de Tecidos - posteriormente Companhia Fluminense de Tecidos ${ }^{6}$ foi inaugurada no bairro do Barreto no ano de 1893, junto com outras tantas de fósforos, ladrilhos e olarias, que logo trataram de dar uma outra configuração ao

\footnotetext{
${ }^{5}$ Cada Rede (A e B) contabiliza um total de doze entrevistas.

${ }^{6}$ Em 30/4/1968 a então direção da Companhia Manufatora Fluminense alterou sua denominação para Companhia Fluminense de Tecidos.
} 
bairro que passava a ser conhecido como o bairro "operário" da cidade de Niterói, então capital do Estado do Rio de Janeiro 7 .

A Companhia foi criada por iniciativa de um grupo de empresários brasileiros, organizada sob regime de sociedade anônima e de capital aberto (D. 0. nº 110, 25/4/1891) (BRASIL, 1891). Na década de 1930, a fábrica foi adquirida pelo empresário do ramo têxtil Severino Pereira da Silva, também proprietário da Fábrica de Tecidos Aliança, situada no bairro das Laranjeiras, na cidade do Rio de Janeiro (MATTOS, 1949). Finalmente, em junho de 1946, a fábrica foi vendida ao Comendador Assad Abdalla, empresário sírio que estabeleceu seus negócios em São Paulo desde fins do século XIX, sendo a mesma propriedade da família até hoje.

Erguida seguindo o padrão clássico de "fábrica com vila operária", conforme distingue a literatura a respeito, a CFT construiu em torno de si uma forte infra-estrutura à qual o trabalhador se submetia, que interferia não só no regime de trabalho, mas também em sua vida privada. Além das vilas operárias, construídas a partir de 1912 (D. 0. de 31/12/1912) (BRASIL, 1912) a direção da Companhia colaborou com a criação de times de futebol locais, clubes recreativos e centros musicais, revelando a influência da mesma na constituição do bairro operário que se conformava já nas primeiras décadas do século XX.

Percebendo a importância destes espaços para os trabalhadores da fábrica e moradores do bairro, os Assad Abdalla, em conformidade com os proprietários da fábrica do início do século, buscaram dar continuidade e, de certa forma, até ampliar as referidas obras. Ainda nos primeiros anos à frente do estabelecimento fabril os novos proprietários da Companhia apoiaram a construção da sede do Manufatora Atlético Clube (1948), além de outras iniciativas presentes na memória dos entrevistados como tendo sido realizadas em prol do operariado, tais como: a criação da Cooperativa da fábrica (1951), a aprovação do projeto para a construção de uma nova vila operária e ainda, na década seguinte, a inauguração da Escola Primária Comendador Wagih Assad Abdalla (1966) para os filhos dos funcionários da fábrica.

Ocupando lugar de destaque nestas complexas relações de reciprocidade (THOMPSON, 1987, p. 17) entre patrões e trabalhadores, identificamos na figura de Eduardo Haddad, genro do Comendador Assad Abdalla, uma importância fundamental na tessitura destas relações. Em grande parte das entrevistas que realizamos, Eduardo Haddad é constantemente lembrado como um homem

\footnotetext{
${ }^{7}$ Niterói foi capital da província e depois do Estado do Rio de Janeiro de 1835 a 1975, com uma breve interrupção de 1894 a 1903.
} 
simples e de origem humilde, como afirma José Luís Corrêa dos Santos e Maria José Barreto:

0 grupo de São Paulo era Assad-Abdalla, então Seu Eduardo trabalhava com o grupo, era empregado, tanto que ele dizia: É, Zé, eu fui servente de pedreiro. Ele era balconista da loja do grupo, lá em São Paulo. Aí ele era assim uma pessoa simpática, um moreno simpático, Seu Eduardo, era vistoso, ele era... e namorou Dona Helena, que era filha do Comendador Assad- Abdalla. Ele casou com dona Helena e compraram essa fábrica e deram para ele tomar conta, aí ele veio pra cá pra Niterói ${ }^{8}$.

Seu Eduardo, o dono, você era humildezinho, e esperava ele passar lá fora, lá em baixo, porque quando chegava lá no escritório ninguém queria deixar subir. Ele vinha, pra fábrica, dirigindo um automóvel... antigo e o casaco dele enfiava dentro daquele... daquele... banco e rebentava a costura, ele chegava na mesa da gente e jogava pra gente consertar sem a gente saber o que ele queria?.

Figura 1 - Companhia Manufatora Fluminense de Tecidos, década de 1920 (fundos da fábrica, na Rua Guimarães Júnior).



Fonte: Biblioteca Estadual de Niterói, 1922.

\footnotetext{
${ }^{8}$ Entrevista concedida por José Luís Corrêa dos Santos, com gravação realizada em 07/01/2005 na cidade de Niteroi, RJ.

${ }^{9}$ Entrevista concedida por Maria José Barreto, com gravação realizada em 20/12/2004 na cidade de Niteroi, RJ.
} 
Roupas velhas, automóvel antigo, carisma, benevolência. São muitas as histórias que envolvem Eduardo Haddad e contribuem com a imagem que se criou em torno do "patrão-trabalhador". As festividades de Natal e $1^{\circ}$ de Maio, 0 contato físico com os trabalhadores, a imagem de bom homem que ia trabalhar todos os dias, contribuíram ainda mais para compor o que o antropólogo José Sérgio Leite Lopes (1988, p. 60) chamou de mise n'scene das relações de classe, e garantir, através destes "rituais de agregação" a aproximação e cumplicidade dos funcionários ao ambiente de trabalho, sendo este um componente essencial para a confirmação das relações de classe já existentes.

Fazendo o contraponto com o "tempo do Seu Eduardo Pai", descrito como "próspero", "tranqüilo", "feliz" o "tempo dos filhos de Eduardo Haddad" é visto pelos entrevistados como o início de um período de falência fabril e desestruturação do bairro. Por outro lado, outros aspectos associados aos modelos de gerência em voga naquele período também contribuíram para esta mudança de paradigma na relação patrão-empregado e, justamente por isso, não podem deixar de ser considerados.

Figura 2 - Titulares do time profissional do Manufatora Futebol Clube, no ano de 1951.

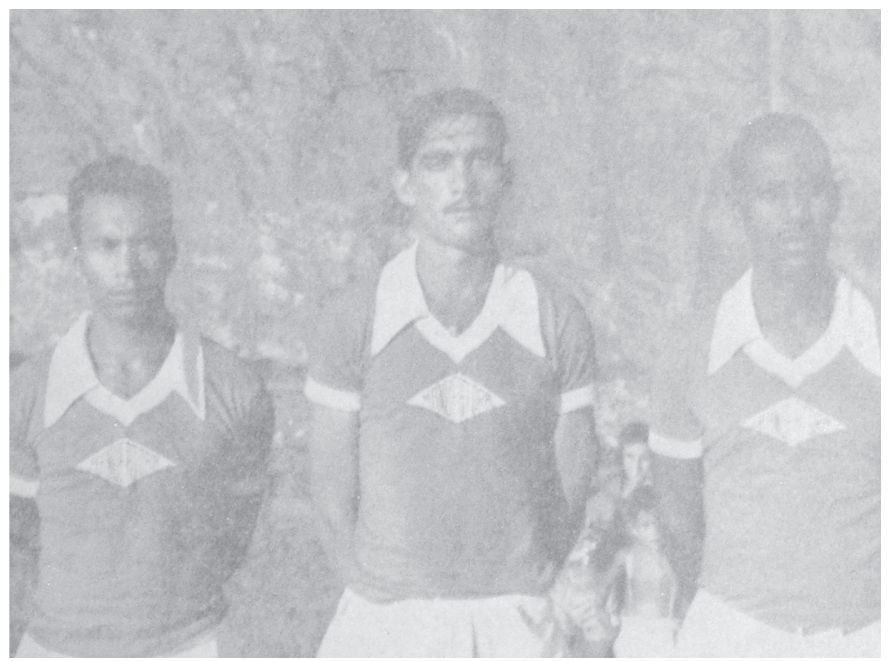

Fonte: MANUFATORA..., 1951. 
Figura 3 - Coroação da Rainha do Manufatora Atlético Clube por Helena Abdalla Haddad.

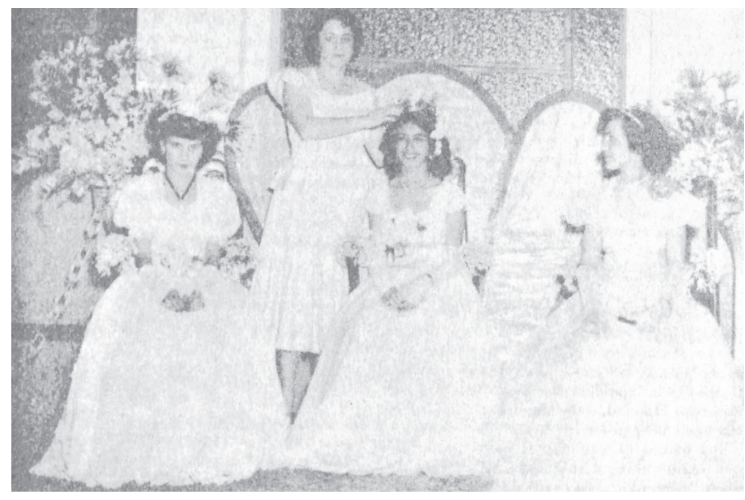

Fonte: MANUFATORA..., 1950.

Renovação, empreendorismo, tecnicismo. Estas são algumas palavraschave que entraram na ordem do dia do empresariado brasileiro a partir da década de 1960, sobretudo àqueles que receberam alguma formação acadêmica neste período, como é o caso de Eduardo e Ricardo Haddad. Segundo Luc Boltanski e Ève Chiapello (2009, p. 91-98), a literatura empresarial desta época tinha como premissas básicas a crítica ao modelo anterior de gestão, pautada no capitalismo familiar, em uma estrutura administrativa burocratizada e centralizada; e a promoção por antiguidade. Em contrapartida, esta geração de empresários valorizava a eficiência logística da produção, a formação técnica, e a promoção por mérito.

No que se tratando do "tempo do Eduardo "pai" e "tempo dos filhos", observamos que as referidas mudanças lembradas pelos trabalhadores não envolveram apenas diferentes modelos de gerência ou tratamento distinto dos patrões com os demais funcionários da Companhia. Aspectos conjunturais, aliados a um novo discurso empresarial em voga a partir de fins da década de 1960, também corroboraram para uma série de novas medidas impetradas na administração daquele estabelecimento fabril, a partir dos anos 1970.

Procurando traçar características mais gerais sobre os setores considerados "não-dinâmicos" da economia brasileira, tais como o têxtil, Francisco de Oliveira (2003, p. 114) pondera que este tipo de indústria, também denominada "tradicional", apresenta constantes problemas de realização, não só por experimentarem crescimento lento, mas por dependerem da demanda das classes 
mais baixas e, por isso, necessitarem constantemente de auxílio governamental para subsidiar suas exportações. Sensíveis às pressões governamentais para garantir que o setor se mantivesse competitivo e engajado no discurso empresarial em voga, cuja tônica era o progresso, o crescimento e a modernização, Eduardo Filho e Ricardo Haddad, empregaram esforços em prol de mudanças dentro da estrutura produtiva da CFT. Além da renovação de alguns equipamentos, percebemos que os novos patrões passaram a exigir formação técnica de seus trabalhadores, demonstrada pela admissão de profissionais técnicos com diploma oriundos do Serviço Nacional de Aprendizagem Industrial (SENAI) da cidade do Rio de Janeiro, e a conseqüente demissão ou retreinamento de funcionários mais antigos que não contavam com a escolarização formal exigida.

Outros espaços situados fora do "chão-de-fábrica", mas, que como já mencionamos, também sob interferência patronal, são apontados pelos trabalhadores entrevistados como tendo sofrido os efeitos destas estratégias de modernização. Além do fim das festividades e da transferência da administração das casas das vilas operárias para uma imobiliária, os trabalhadores entrevistados responsabilizam os sucessores de Eduardo Haddad pelo fim do Manufatora Atlético Clube, em 1983.

A conjuntura internacional desfavorável e a política econômica concentracionista, intensificada no país nos anos 1970, tiveram fortes conseqüências na economia brasileira na década de 1980 e para produtividade da CFT. 0 déficit na balança de pagamentos, as tentativas de redução das importações - responsável pelos índices negativos de nossa balança comercial desde 1971 e a forte recessão, reduziram em 10\% a produção industrial brasileira em 1981 (CARNEIR0; MODIANO, 1990, p. 327) e em 881.581 kg o consumo de algodão da CFT neste mesmo ano (SINDICATO DAS INDÚSTRIAS DE FIAÇÃO E TECELAGEM DO RIO DE JANEIR0, 1982).

Apesar das tentativas de obter subsídios do governo federal, o empresariado têxtil - notadamente a indústria têxtil fluminense - registrava quedas sucessivas em sua produção neste período. Em 1988, a grave crise no setor pôs fim ao turno da noite da CFT, demitindo com isso mais de uma centena de trabalhadores. As demissões, que acabaram ocasionando uma greve dos trabalhadores da fábrica que paralisaram suas atividades por três semanas, foram justificadas pelo diretor da Companhia, Antonio Carlos Santos, como resultado da crise que a indústria têxtil vinha passando e ainda, na ocasião, acrescentou que: “[...] não só em Niterói, como em todo Brasil, está sofrendo com a crise, operando com ociosidade. Não 
há demanda de consumo que justifique. Decidimos então recorrer ao extremo" (OPERARIOS..., 1988).

A prioridade governamental em investir em fibras químicas (poliéster, nylon, lycra) e a abertura comercial, verificada nos anos 1990, levou à diminuição progressiva das indústrias têxteis que não conseguiram investir o suficiente em modernização e na produção de fios diferenciados. Segundo Análise encomendada ao Instituto Euvaldo Lodi (2000), o número de empresas deste ramo no Brasil decresceu 57\%, no período referente a 1990 e 1997. Endossando as estatísticas, em 1997, a Cia. Fluminense de Tecidos paralisou a sua produção.

\section{A CLASSE OPERÁRIA CHEGA AO PARAÍSO}

Mônica Andrade, ex-funcionária do setor de compras da CFT, desejou muito que seu filho mais velho trabalhasse na fábrica. Passados alguns anos após seu fechamento e na esperança de que a qualquer momento pudesse reabrir, Mônica incentivava o seu filho, que estava em busca do primeiro emprego, a deixar seu currículo na CFT. Assim como ocorreu com ela, há mais de vinte e cinco anos atrás, Mônica desejava que seu filho conseguisse "ganhar experiência" e de preferência, de carteira assinada. Filha e neta de antigos operários da CFT e moradores do Barreto, Mônica Andrade lembra que todos da sua família já haviam trabalhado na fábrica e que por isso, com ela, não foi diferente, e nem com o seu filho deveria ser.

Neir Meirelles Leckar diz (e gosta de dizer) que já fez de tudo. Empregado atualmente como almoxarife em uma empresa de prestação de serviços, Neir também vende churrasquinho no seu bairro aos fins de semana, para segundo ele, ajudar no sustento da família. Já trabalhou como motorista, faxineiro e cozinheiro em sua estada de nove meses dos Estados Unidos, sem mencionar as inúmeras outras ocupações que teve antes de partir em busca do american dream.

Uma delas nos interessa de perto: a função de ajudante de contramestre na Cia. Fluminense de Tecidos, que ocupou por quase dez anos. Na realidade, esta não foi apenas uma ocupação, foi o seu "primeiro emprego de carteira assinada", do qual "agradece muito" e sente falta. Se voltar, se me chamar, eu com certeza vou ir pra lá, diz Neir que, assim como Mônica Andrade, é filho e neto de antigos trabalhadores da CFT.

Mesmo enfatizando o trabalho pesado, a tensão sempre presente nos setores pela necessidade de "atingir meta" de produção, as condições de trabalho 
insalubres, a baixa remuneração, Neir sente saudades do trabalho na fábrica. Para ele, quando a CFT fechou, [...] destruiu um pouco assim, destruiu a bistória, referindo-se a ele e a [...] muita gente ali que trabalhava, ou que tinha parente que trabalhava na fábrica e ficou desempregada.

Além do temor pela falta de oportunidades de emprego no presente e de expectativas melhores para 0 futuro, Mônica e Neir enfatizam a importância da "origem" familiar, da cultura ancestral, da aprendizagem pelo trabalho, referindose não só ao desenvolvimento de um ofício, mas à construção de valores que lhe são caros. 0 passado, as "raízes" que acredita ter herdado de seus pais e recebido por intermédio da atividade laboral, demonstram a importância do babitus nas respostas dadas por eles, sobretudo quando interpelados por situações adversas.

Segundo Bourdieu, a construção do babitus constitui "[...] o princípio gerador e unificador do conjunto das práticas e das ideologias características de um grupo de agentes" (BOURDIEU, 1999, p. 191). Contrariando àqueles que podem fazer considerações apressadas sobre este conceito, atribuindo-lhe generalizações ou determinismos sociais, o sociólogo explica que o habitus só pode ser entendido como algo que é "socialmente construído".

De fato, as disposições mais inconscientes, como por exemplo as que resultam da interiorização de um habitus primário de classe, se constituíram através da interiorização de um sistema objetivamente selecionado de signos, índices, sanções, que nada mais são do que a materialização, nos objetos, nas palavras e nas condutas, de um sistema particular de estruturas objetivas. Tais disposições permanecem o princípio de seleção de todos os signos e índices produzidos pelas situações extremamente diversas que são capazes de determinar a sua atualização (BOURDIEU, 1999, p. 191).

0 processo de "seleção dos signos" de que nos fala Bourdieu, capazes de determinar a atualização do habitus, aliado às novas experiências adquiridas por estes trabalhadores ao se depararem por exemplo, com a situação de crise econômica e desemprego propiciada pelo processo de falência da CFT e esvaziamento industrial do bairro, proporcionam, ao nosso ver, um esforço "semiconsciente" destes trabalhadores por (re)forçar e (re)formular suas identidades socais, motivados pelo papel de centralidade que a cultura do trabalho tem em suas vidas. Em síntese, nas palavras de Bourdieu: "[...] não é a condição de classe que determina o indivíduo, mas o sujeito que se autodetermina a partir da tomada de consciência, parcial ou total, da verdade objetiva de sua condição de classe" (BOURDIEU, 1999, p. 189). 
Neir Leckar trabalha até 14 horas por dia (inclusive aos fins de semana) para conseguir dar um pouco mais de conforto à sua família. Eu queria ter um trabalbo, pra mim ter um salário, não pra mim desfrutar de conforto, mas pra mim pagar uma faculdade pra minhas filhas [...], lamenta o ex-ajudante de contramestre da CFT que mesmo enfatizando a baixa remuneração oferecida pela fábrica, revela seu inconformismo com o seu fechamento.

Tinha muita gente ali que trabalhava ou que tinha parente que trabalhava na fábrica e muita gente ficou desempregada. E isso aí foi muito ruim, em termos pro comércio do Barreto, se vê que ali... hoje tá dando uma melhoradazinha por causa dos prédios, né? Mas eu acho que se tivesse a fábrica funcionado, os comércio ali, é mais emprego, né? Porque não é nada não é nada, ali chegou a ter mais de três mil funcionários, nos três turnos. Muita gente depende e até hoje, quando eu encontro, tem saudade daquele tempo que trabalhamos junto ali ${ }^{10}$.

Além de não encobrir o desejo de voltar a trabalhar na fábrica, Neir chama a atenção para a quantidade de pessoas que depois da falência da CFT, nunca mais conseguiu emprego. Ao contrário dele, que concluiu o ensino fundamental e conseguiu "mudar de ramo", muita gente que só tinha até a $3^{a}$ série, $4^{a}$ série [...], não retornou ao mercado de trabalho, segundo Neir, pelas exigências deste por melhores qualificações da mão-de-obra.

Waldemar Silva trabalhou na tecelagem da CFT por 28 anos. Começou aos 19 anos como tecelão e após dois anos de trabalho foi promovido a ajudante de contramestre para finalmente, depois de seis anos de fábrica, chegar ao cargo de contramestre. Quando perguntado sobre a sua conduta junto aos companheiros de trabalho, em uma função considerada como "de confiança" dentro do espaço fabril, Waldemar afirmou que:

Eu não tinha problema nenhum porque quando mudou o encarregado aí, o encarregado me chamou lá e falou pra mim porque que eu trabalhava tanto tempo com essas senhoras e nunca tinha dado uma advertência a nenhuma. Elas não chegavam atrasadas não, porque era muito difícil porque elas gostavam de trabalhar, as mulheres gostavam de trabalhar e ganhar dinheiro. Então ele me chamou e falou assim: Por que quê o senhor nunca deu uma advertência a um funcionário aqui? Aí eu falei: ó doutor eu não dei porque

\footnotetext{
${ }^{10}$ Entrevista concedida por Neir Leckar, com gravação realizada em 30/09/2008 na cidade de Niteroi, RJ.
} 
não tinha necessidade de dar, porque eu trabalho com essas senhoras há tanto tempo não tô trabalhando hoje mesmo. As meninas são tão legal comigo, com meu trabalho, que chega fim de ano elas fazem uma lista e me dão presente de fim de ano, entendeu? E quando quer ir no banheiro elas me chamam e quando eu tiver uma folga pra ficar olhando o maquinário pra ela, pra elas ir no banheiro e voltar correndo pra não parar a máquina. Então ele me chamou e falou assim [...]. Ah, nós sabemos o setor do senhor é o que produz mais aqui. E era mesmo. Era o setor que Seu Eduardo, velho, quando ele chegava na fábrica 8 horas da manhã ele ia direto lá no setor, ia lá dentro do setor para saber como é que tava.

No trecho destacado, Waldemar enfatiza que o "gosto pelo trabalho" das operárias, não só poupava-o de distribuir advertências, mas era de fundamental importância para a produtividade do setor e rentabilidade da fábrica. Ao valorizar a autodisciplina das operárias com quem trabalhava e a disposição voluntária das mesmas para produzir e "ganhar mais", o discurso do ex-contramestre guarda em si algo ulterior ao ethos do trabalho. Por outro lado, não podemos deixar de reconhecer que, para além do discurso incorporado que remete valor às pessoas pelo trabalho que executam - comumente associado à velha ética do trabalho (SENNET, 1999, p. 117-140), a narrativa de Waldemar idealiza o espaço de fábrica ao afirmar, por exemplo, que ele, um contramestre que tinha como função consertar a máquina e olhar a disciplina do setor [...], nunca precisou sequer, aplicar uma advertência.

É claro que não estamos questionando aqui o carisma e a possível benevolência de Waldemar como supervisor. 0 que na realidade se torna uma questão para nós, é a sua "imaginação criativa" (PORTELLI, 1993), o seu esforço por reinventar as suas próprias atribuições que perpassam a de responsável pela disciplina dos funcionários, e chegam à louvável posição de incentivador da produtividade da fábrica e, principalmente, do ganho salarial das operárias que, assim como ele, "gostam de trabalhar e ganhar dinheiro". Quem na realidade desequilibra a pretensa harmonia do setor é o encarregado recém-chegado à fábrica, que lhe cobra explicações sobre a ausência de punições na seção que reconhecidamente é uma das mais importantes em uma fábrica de tecidos.

Ao demarcar certa distância entre ele (um trabalhador) e seu supervisor, um jovem "doutor" contratado pela fábrica, que diferente dele, possuía formação no SENAI, e ao qualificar a boa produção de sua seção como resultado da antiguidade das relações - profissionais e de amizade - entre ele e as senhoras com 
quem trabalhava, Waldemar salienta não só que a presença do jovem formado por curso técnico era dispensável. Isto não só por que o mesmo teve dificuldade em compreender que era justamente o companheirismo e solidariedade operária que garantiam ali uma boa produção, mas também o seu próprio valor, de um trabalhador que iniciou carreira cedo, aos treze anos de idade, que aprendeu por ofício, não por cursos e que por isso, deveria ser valorizado.

$\mathrm{Na}$ entrevista realizada em seu atual local de trabalho - uma marmoraria onde lhe permitiram instalar a sua banca de doces - dava para avistarmos a fachada da velha fábrica. Olhando para ela, Waldemar se diz agradecido pelos anos de trabalho na Companhia, lembrando com saudade dos laços de amizade com os companheiros de trabalho e com o "velho" patrão. Não esconde a satisfação de ter conseguido aposentadoria integral pela fábrica, após sofrer um acidente que 0 afastou do trabalho por invalidez. Foi preciso entrar na justiça para não ser obrigado a trabalhar sem condições. Mesmo assim, antes que saísse pelos portões, Waldemar diz, orgulhoso, que ouviu do gerente que as portas da fábrica sempre estariam abertas para ele, se caso um dia quisesse retornar, afinal de contas, ele [...] era bom operário, praticamente um operário padrão.

Aos setenta anos de idade, vendendo doces, tal qual fazia quando ainda era menino e tentava ganhar alguns trocados pelas ruas de Maceió (Alagoas) para ajudar a sua "avó-mãe" no sustento da casa, o operário - como se autodenomina por inúmeras vezes - não poderia contar uma história diferente sobre uma vida inteira de trabalho dedicado à fábrica que, junto ao setor que "produzia mais", acredita ter ajudado a construir. Por outro lado, Waldemar se sente impelido a narrar as arbitrariedades sofridas por seus antigos companheiros de trabalho, não só porque perderam seus empregos, mas por não terem o valor do seu trabalho reconhecido e devidamente recompensado. Assim, ele não fala só pelo grupo, mas também por si.

0 negócio deles (dos filhos do Seu Eduardo) era a empresa, de modernizar a empresa, trazendo funcionário do SENAI do Rio pra cá. Então, os funcionários do SENAI do Rio vinha com teoria, mas faltava a prática, eles chegavam aqui eles impunham, eles não queriam aceitar, aí houve essa reviravolta na empresa e a empresa acabou afundando.

Para Waldemar, os motivos pelos quais a administração dos filhos à frente dos negócios da CFT foi um fracasso são claros: a opção pela "modernização" da mão-de-obra, com a contratação de novos trabalhadores com formação 
técnica, em substituição dos mais antigos, que não possuem diploma, mas possuem vasta experiência e conhecem de fato, o trabalho que realizam. A questão geracional (BOURDIEU, 1983; MANNHEIM, 1984) aqui se apresenta como um fator importante de distinção interna, colocando, de um lado, trabalhadores "novos" e munidos de diploma de curso técnico e, de outro, "velhos" operários que aprenderam o ofício no próprio "chão-de-fábrica". As diferenças apontadas entre as administrações das duas gerações de patrões - pai e filhos - conforme já observamos, também auxiliam nesta relação de contraste. Porém, mesmo que estes conflitos geracionais sejam de grande importância para a nossa pesquisa, ater-nos-emos aqui em perceber como a identidade de classe ganhou especial protagonismo na fala dos entrevistados, assim como a categoria trabalho adquiriu dimensões idealizadas, privilegiando assim, o caráter coletivo da auto-construção (THOMPSON, 1987, p. 12) da trajetória deste grupo social.

Nestesentido, verificamos que apesar depertencentes a gerações (biológicas) diferentes, a iniciativa de "lamentar pelo grupo", presente nas narrativas de Neir e Waldemar, é comum a todos os entrevistados. Somente "os outros", jamais eles próprios, sofreram demasiadamente com o fechamento da fábrica a ponto de não conseguir mais emprego, ficar doente, ter a família desestruturada, padecer de diferentes males, tais como depressão ou alcoolismo. Ao enfatizar a infelicidade dos antigos companheiros de trabalho, os trabalhadores entrevistados buscam, em atitude coerente com o que disseram anteriormente, salientar as "perdas" sofridas pelo grupo operário com o fechamento da fábrica, referindo-se à desvalorização daqueles que dedicaram uma vida inteira de trabalho à fábrica e, ainda assim, não receberam indenizações após a falência da companhia, e/ou foram despejados das casas das vilas operárias após demissão, e/ou atualmente ainda vêem-se desempregados, etc. Por outro lado, fica patente a necessidade dos mesmos, em valorizar as recompensas "pessoais" que receberam pelos anos de trabalho na fábrica - já que muitos se atêm apenas superficialmente no que se refere aos ganhos materiais - a fim de justificarem o desejo pelo retorno de seu funcionamento.

No caso de Neir que deseja um emprego melhor, pois o atual não lhe oferece a remuneração almejada, a volta da fábrica não representaria, necessariamente, a obtenção de ganhos salariais. Além de ter participado ativamente no movimento de greve de 1988, o mesmo nos relatou que enquanto esteve no quadro de funcionários da companhia enfrentou, durante três anos ininterruptos, uma dupla jornada de trabalho: na fábrica das 5 às $13 \mathrm{~h}$ e na padaria que funcionava em frente à CFT, 
das 14 às 22h. Estes anos de dedicação quase integral ao trabalho, empreendidos garante Neir, para possibilitar um futuro melhor para suas filhas, não para [...] desfrutar de conforto, fizeram-no finalmente com que se declarasse cansado. Para o ex-operário (como se autodenomina), a volta da fábrica representaria a possibilidade de voltar a estudar e, ainda, de investir novamente em uma profissão.

Apesar de só ter ocupado o cargo de eletricista em seu último ano de trabalho na fábrica, Neir atualmente não trabalha em uma função da qual possa usufruir de fato, de sua formação. Atuando hoje como almoxarife na empresa em que trabalha, o mesmo nos relata que já foi controlador de transportes, operador de rádio, trabalhou fazendo leitura e como ajudante de eletricista, sendo este último o mais próximo que conseguiu chegar de sua antiga formação no presente emprego. Arrependido por não ter investido em sua formação quando mais jovem, apesar dos estímulos do pai e do oferecimento da CFT para se aperfeiçoar no SENAI, Neir pensa em voltar a estudar para assim, acredita, alcançar uma remuneração compatível ao seu ritmo de trabalho.

Ao contrário dos trabalhadores não-qualificados da Willys, investigados por Antonio Luigi Negro (2004), que de certa forma se viam em suas "cuidadas instalações", na imagem de "estabilidade e força" da empresa, José Luís Corrêa dos Santos, Maria José Barreto, Mônica Andrade, Neir Leckar, Waldemar Silva e os outros demais trabalhadores, entrevistados para esta pesquisa, não conseguem se enxergar na atual imagem abandonada e depredada da Companhia. Talvez por isso escutemos sempre de todos a esperança que um dia, a fábrica volte a funcionar - sem que minimizemos, é claro, a evidente possibilidade de trabalho que tal retorno representaria para os moradores do bairro. Diante da impossibilidade de se identificar com a atual impressão de decadência, incompatível com uma vida dedicada ao "bom trabalho" e ainda, na ausência de melhores formas de identificação do presente, marcado pela multiplicação e precarização das formas de trabalho, que não oferecem designações mais seguras - tais como, "ser um operário" (SENNET, 1999, p. 140), os ex-trabalhadores entrevistados idealizam 0 trabalho na fábrica e dotam de dignidade e positividade a sua identidade operária.

Ricardo Antunes (2005), com base em Marx, fala da importância da categoria trabalho na realização do ser social. Não o trabalho assalariado, fetichizado, mas aquele que é inerente à atividade humana, fundamento básico da sua omnilateralidade, "necessidade natural e eterna de efetivar o intercâmbio entre homem e natureza" (ANTUNES, 2005, p. 167). "0 trabalho é, portanto, 
um momento efetivo de colocação de finalidades humanas, dotado de intrínseca dimensão teleológica. E como tal, mostra-se como uma experiência elementar da vida cotidiana, nas respostas que oferece aos carecimentos e necessidades sociais." (ANTUNES, 2005, p. 168).

Apesar das tentativas modernizantes, a CFT sempre optou por manter uma organização produtiva planificada e relações de trabalho pautadas aos moldes mais tradicionais. Seria preciso, portanto, muita "imaginação criativa" para associar o trabalho na fábrica - em sua dimensão abstrata, entranhada, desrealizadora da atividade humana - com a dimensão concreta do trabalho, delineada por Antunes como sendo a base para as necessidades humanas e sociais, que transcendem 0 trabalho voltado para a produção de valores de troca. Percebemos, no entanto, que a "velha ética do trabalho" capitalista, fundada na valorização de uma vida repleta de sacrifícios e no infindável adiamento do desejo de satisfação e realização, é submetida a um exercício de "reinterpretação criativa" (LOPES, 1988, p. 23) por parte dos antigos trabalhadores da Companhia, que passaram a enxergar no trabalho que desempenhavam na antiga fábrica - não a de hoje, nem a de antes, mas aquela descrita por eles como produtiva, geradora de empregos, responsável pela "vida" do bairro que, apesar dos problemas, ofereciam um sentido pleno de realização humana pelo trabalho, a sua "verdadeira" imagem.

Figura 4 - Detalhe da fachada principal da Companhia Fluminense de Tecidos, 2006 (frente para a Rua Dr. March).

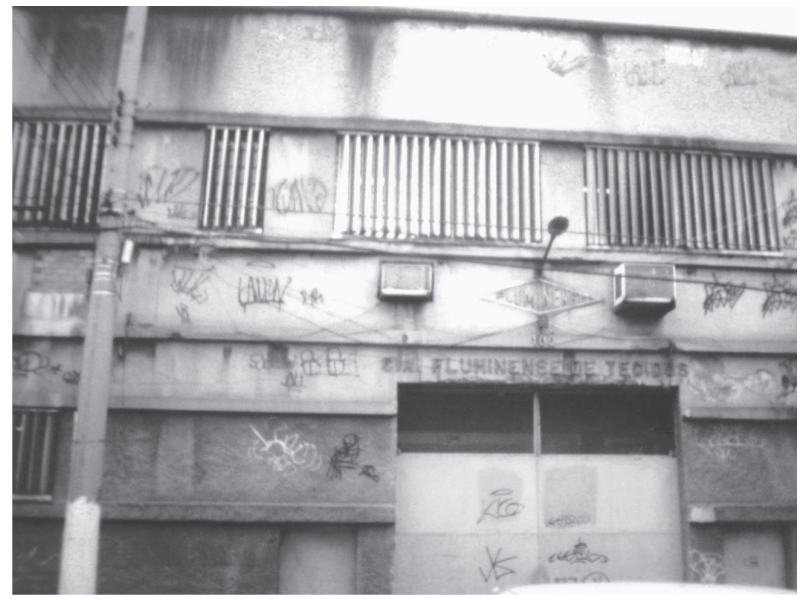

Fonte: Arquivo pessoal da autora. 
Sem dúvida, a vida seria insuportável se não pudesse ser assim recriada. A desestruturação do antigo bairro operário e as dificuldades em conseguir um trabalho melhor, não combinam com uma vida inteira de "bons serviços" prestados à companhia. Depois de tantos anos de dedicação e da certeza destes de terem ajudado no desenvolvimento econômico da cidade, do estado, do país - e de não terem sido justamente recompensados por isso - que homens e mulheres que até hoje não desistiram e não podem desistir do trabalho, reforçam continuamente em seus discursos a sua identidade operária e a cultura do trabalho que lhe é inerente.

\section{Considerações Finais}

Em 1997, a Companhia. Fluminense de Tecidos parava as suas máquinas. Junto a ela, algumas dezenas de homens e mulheres interrompiam as suas funções. Já há alguns anos o apito que anunciava a mudança de turno não tocava. Aquelas pessoas saíam, portanto, sem causar nenhum alvoroço, sem quem ninguém sequer soubesse que a última fábrica da região estava, após alguns anos insistentes, finalmente fechando as suas portas.

Buscamos, ao longo deste artigo, perceber o impacto da crise e do posterior fechamento da CFT em seus trabalhadores. Ainda que hoje desempenhem diferentes funções daquelas que ocupavam anteriormente na Companhia, os trabalhadores entrevistados reforçam a sua identidade operária e é a partir dela que procuram se identificar.

Em tempos de "crise de identidades", falar em identidades de classe pode parecer anacrônico diante dos efeitos desestabilizadores da "globalização" e da "acumulação flexível" nas identidades dos "sujeitos pós-modernos". Segundo algumas reflexões recentes - sobretudo àquelas que se filiam ao jargão "pósmoderno", diferentes formas de identificação que até então se supunham fixas ou estáveis, pulverizam-se diante dos novos apelos e demandas dos novos tempos.

Concordamos que as transformações verificadas no mundo do trabalho nas últimas décadas atingiram, em diferentes maneiras e graus de intensidade, a classeque-vive-do-trabalho global. 0 desemprego, o assalariamento, a multiplicação das formas de trabalho parcial, temporário, precarizado, a desestruturação da organização sindical tradicional, a destruição de antigas comunidades operárias, a desindustrialização emitiram, sem dúvida, um efeito pluralizante nas relações 
de trabalho tradicionais e, por consequência, complexificaram ainda mais a classe trabalhadora, sem que isto implique necessariamente, em sua completa extinção. Nos termos de Ricardo Antunes (2005, p. 58), "enquanto perdurar o modo de produção capitalista, não se pode concretizar a eliminação do trabalho como fonte criadora de valor".

Valores de troca, misteriosamente velado nas mercadorias que encobrem as características sociais do trabalho empreendido pelos homens e mulheres; valores de uso, quando não fetichizado na forma de mercadorias, mas sim como resultado do trabalho útil e indispensável à existência humana (MARX, 1987, p. 50). De uma forma ou de outra, o trabalho sempre produz valor. Mesmo diante da heterogeneidade presente no interior da classe trabalhadora na atualidade, não nos parece apropriado pensar em seu completo "fim"; nem tampouco podemos concordar com a idéia de as identidades de classe como sendo recriadas artificialmente ou por intermédio de acordo tácito.

Cabe esclarecer que não saímos à busca de resquícios das antigas "identidades fechadas", "culturas puras", "comunidades unificadas" que já há algum tempo perderam sentido. É claro que estamos de pleno acordo com Stuart Hall (1998), quando este afirma que hoje somos continuamente confrontados com identidades múltiplas e por vezes, profundamente contraditórias. Não é por acaso que empregamos aqui o termo identidades de classe no plural. Por outro lado, acreditamos que mesmo marcado pela multiplicidade, tal processo não deve pormenorizar a centralidade que a categoria trabalho exerce na re-elaboração das identidades sociais dos trabalhadores em geral e deste grupo em especial, tanto no que tange à sua dimensão concreta quanto simbólica.

Esta consciência de classe, que unifica os ex-trabalhadores da fábrica em torno de sua auto-identificação como "operários" - embora salientemos que em uma fábrica de tecidos como a CFT, o espaço de fábrica é marcado por diferenciações e hierarquias rígidas entre os funcionários - os mobiliza pela busca por compensações (para si e para o grupo) dos anos de "bom trabalho" prestados à companhia. Por vezes, as narrativas nos parecem mais um resultado bem sucedido de uma inculcação da moral do trabalbo gerida pela fábrica ao longo dos anos, porém, mesmo sem deixar de abalizá-la, vimos que esta acaba entrecruzada a outros aspectos que pretendem dotar de valor a vida de trabalho na fábrica, a antiga função que desempenhavam e por extensão, a si mesmo enquanto trabalhadores. 


\section{REFERÊNCIAS}

ANTUNES, Ricardo. Adeus ao trabalho? ensaios sobre as metamorfoses e centralidade do mundo do trabalho. São Paulo: Cortez, 2005.

BENJAMIN, Walter. Charles Baudeleire um lírico no auge do capitalismo. São Paulo: Brasiliense, 1989.

BIBLIOTECA ESTADUAL DE NITERÓI. Centenário da Independência do Brasil. Fotografias da Companhia Manufatora Fluminense. Álbum do Estado do Rio de Janeiro, Niteroi, 1922.

BOLTANSKI, Luc; CHIAPELLO, Éve. O novo espirito do capitalismo. São Paulo: Martins Fontes, 2009.

BOURDIEU, Pierre. A economia das trocas simbólicas. São Paulo: Perspectiva, 1999 .

. A juventude é apenas uma palavra. In: BOURDIEU, Pierre. Questões de Sociologia. Rio de Janeiro: Marco Zero, 1983.

. Compreender. In: BOURDIEU, Pierre (Org.). A miséria do mundo.

Petrópolis: Vozes, 1997.

BRASIL. Ministério da Fazenda. Balanço de 31 de dezembro de 1912. Diário Oficial da União, Brasília, 31 de dezembro 1912.

BRASIL. Ministério da Fazenda. Primeira Assembléia Geral de 11 de abril de 1891. Diário Oficial da União, Brasília, 25 abril 1891.

CARNEIR0, Dionísio Dias; MODIANO, Eduardo. Ajuste externo e desequilíbrio interno. In: ABREU, Marcelo de Paiva. A ordem do progresso: cem anos de política econômica republicana: 1889-1989. Rio de Janeiro: Campus, 1990.

CHAUÍ, Marilena. Conformismo e resistência: aspectos da cultura popular no Brasil. São Paulo: Brasiliense, 1989.

HALL, Stuart. A identidade cultural na pós-modernidade. Rio de Janeiro: DPC\&A, 1998.

INSTITUTO EUVALDO LODI. Análise da eficiência econômica e da competitividade e da cadeia têxtil brasileira. Brasília: IEL, 2000.

LOPES, José Sergio Leite. A tecelagem dos conflitos de classe. São Paulo: Marco Zero, 1988. 
MANNHEIM, Karl. 0 problema sociológico das gerações. In: . Coleção grandes cientistas sociais. São Paulo: Ática, 1984.

MANUFATORA: Boletim interno, Niteroi, ano 2, n. 18, jan. 1950. Gravura "Rainha do Manufatora Futebol Clube".

MANUFATORA: Boletim interno, Niteroi, ano 4, n. 32, maio/jun. 1951. Gravura campeonato da cidade: Quincas, Juca e Antonio.

MARX, Karl. A mercadoria. In: MARX, Karl. O capital: a crítica da economia política. São Paulo: Bertrand Brasil, 1987. v. 1.

MATTOS, José. Movimento paredista do Barreto. Diário do Povo, Niterói, ano 2, n. 226, jun. 1949.

MEHY, José Carlos Sebe Bom. Manual de história oral. São Paulo: Loyola, 1996. NEGRO, Antonio Luigi. Zé Brasil foi ser peão: sobre dignidade do trabalhador não qualificado na fábrica automobilística. In: BATALHA, Cláudio H. M.; SILVA, Fernando Teixeira; FORTES, Alexandre (Org.). Culturas de classe: identidade e diversidade na formação do operariado. São Paulo: Unicamp, 2004.

OLIVEIRA, Francisco de. Crítica à razão dualista: 0 ornitorrinco. São Paulo: Boitempo, 2003.

OPERÁRIOS param em protesto no Barreto. O Fluminense, Niterói, 20 out. 1988.

PORTELLI, Alessandro. 0 massacre de Civitella Val de Chiana. In: AMADO, J.; FERREIRA, Marieta de Moraes (Org.). Usos e abusos da bistória oral. Rio de Janeiro: FGV, 1996.

. Sonhos ucrônicos: memórias e possíveis mundos dos trabalhadores.

Projeto História, São Paulo, n. 10, p. 41-58, dez. 1993.

SENNET, Richard. A corrosão do caráter. Rio de Janeiro: Record, 1999.

SINDICATO DAS INDÚSTRIAS DE FIAÇÃO E TECELAGEM DO RIO DE JANEIRO -SIFT - RJ. Carta da diretoria da Cia. Fluminense de Tecidos ao Sindicato das Indústrias de Fiação e Tecelagem do Rio de Janeiro. 3 fev.1981 e 3 fev. 1982. Pasta CFT F6 nº 70A VII. Rio de Janeiro, 1982.

THOMPSON, Edward P. A formação da classe operária inglesa. Rio de Janeiro: Paz e Terra, 1987. v. 1. . Costumes em comum. Rio de Janeiro: Paz e Terra, 2005. 